\title{
MILITARIZACIÓN Y LEGALISMO COMO ENCAUCES DE LA GESTIÓN POLICIAL DE LA CRIMINALIDAD EN BRASIL
}

\section{JASEFF RAZIEL YAURI-MIRANDA}

Doutorando em Sociedade, Política e Cultura na Universidade do País Basco (UPV/EHU). Mestre em Governança e Estudos Políticos (UPV/EHU), Bacharel em História com Formação complementar em Ciência Política (UFMG, Brasil) e Universidad de Santiago de Compostela (USC). Membro do Centro de Estudos de Inteligência (CEEIG-UFMG) e coordenador do Comitê em Direito Internacional e Governança na Associação Internacional de Estudantes de Ciência Política (IAPSS).

\section{RESUMEN}

El objetivo de este artículo es analizar cómo la militarización y el legalismo de las instituciones policiales brasileñas afectan su rol y la gestión de la criminalidad en Brasil. Esta característica doble del sistema brasileño mantendría una funcionalidad que regula, de forma cualitativa, la proporcionalidad del uso de la fuerza y la capacidad de procesar delitos ante la Justicia. Se verifica cómo esas estructuras se mantuvieron desde el inicio de la Nueva República, y se concluye que la militarización y el legalismo de los cuerpos de seguridad policial siguen imprimiendo los límites de la acción gubernamental mientras se amplifican salidas individualistas y conservacionistas como horizontes meta-políticos para tratar la criminalidad.

Palabras clave: militarización, policía, seguridad pública, investigación criminal, criminalidad.

\section{ABSTRACT MILITARIZATION AND LEGALISM AS PATHS FOR THE BRAZILIAN POLICE MANAGEMENT OF CRIME}

This paper aims to analyze how the militarization and legalism structures attached to police institutions affected these institutions and the answers against criminality in Brazil. This double feature of the Brazilian system is supposed to affect the proportionality of coercion and the ability to prosecute crimes before the courts. It is verified how those structures were maintained from the beginning of the New Republic, imposing the limits and the logics to security policies, whereas individualistic and conservationism solutions against crime appear as current meta-political goals in this subject.

Key words: militarization, police, public security, criminal prosecution, crime.

DOI: 10.31060/rbsp.2019.v13.n2.923

Data de recebimento: 12/03/18 - Data de aprovação: 21/04/19

\section{INTRODUCCIÓN}

En 1988, con la última Constitución brasileña, se esperaba comenzar un periodo de refundación democrática, de mejores derechos sociales, y de paz urbana ante la criminalidad que ya se manifestaba en algunas regiones. Desde entonces, mientras se han producido cambios en otras áreas - desde reformas gerenciales en la 
administración pública en los años 90 hasta el incremento de la capacidad de ayuda social a inicio de este siglo - la criminalidad se ha convertido en una cuestión irresoluble. Ante la creciente complejidad de este fenómeno, desde la década de 1970, se pensaba en desarrollar nuevos modelos de seguridad. Por ejemplo, uno en el cual la policía fuera más allá del uso del arma y del enfoque sobre el hecho delictivo. El sociólogo Daniel Cerqueira (2007) cita a Blumstein, Cohen y Nagin (1978), y a Spelman y Brown (1984), como estudiosos del mundo anglosajón que "cuestionaron el modelo tradicional de lucha contra el crimen, marcado por estrategias enfocadas en arrestar y neutralizar delincuentes" (CERQUEIRA; CARVALHO, 2007, p.13). A finales del siglo pasado, en América Latina también se hablaba de remodelar una policía que se orientaba a la neutralización de conflictos. Era esencial pensar prácticas intersectoriales, sobre todo con acciones junto a las comunidades en las periferias de las metrópolis. También era necesario pensar en sectores como la cultura o la educación, situados fuera del rango de acción del agente o comisario. En teoría, se demandaba una remodelación interna del trabajo de la policía. A pesar de esto, los programas contra la criminalidad han enfrentado una inercia en el modo de operatividad policial produciendo resultados mínimos. Tales limitaciones se han verificado incluso en experiencias comunitarias, algunas con relativo éxito, pero de difícil ampliación en escala geográfico-temporal (DAMMERT, 2007; LAGOS \& DAMMERT, 2012), lo que nuevamente pone bajo el foco el peso de la configuración institucional de las propias policías, así como de su relación con otros actores sociales.

En ese sentido, el objetivo de este artículo es analizar estructuras como la militarización y el legalismo de las instituciones policiales brasileñas, y su influencia en el rol de las mismas, así como en la gestión de la criminalidad en Brasil. Es decir, se intenta analizar cómo el doble énfasis - militarización y el legalismo - en el sistema brasileño ha marcado cualitativamente (en proporcionalidad del uso de fuerza y de efectividad de procesamiento de delitos) el tratamiento de la criminalidad en un marco temporal que se inicia con la promulgación de la Constitución de 1988 hasta 2016, año del vuelco político de la última etapa republicana y que permite un mínimo distanciamiento temporal hacia el presente. Para tal, el estudio se basa en un análisis teórico deductivo a partir del marco de los "legacy contraints" (constricciones de legado, en traducción libre) (COLLIER \& COLLIER, 2002; DAVID, 2007). Es decir, este análisis parte del fundamento de que los antecedentes importan para explicar la configuración política actual dentro de un sistema social y expresa una (des)continuidad que marca la trayectoria y el desarrollo de los ámbitos políticos. Sin embargo, ningún modelo único de cambio o el impacto de eventos pasados puede hacer justicia a los múltiples niveles de causalidad en las explicaciones de un fenómeno (PIERSON \& SKOCPOL, 2002; IMMERGUT, 2006; STEIMO, 2008). Por lo tanto, huimos de un marco de causalidad linear estricta y de correlación entre variables para verificar una hipótesis determinada. En cambio, se construye una mirada holística de interdependencia y simultaneidad entre distintas unidades de análisis (como instituciones, leyes y prácticas informales) que son movilizadas a partir de bibliografía reconocida y documentos legales del área para cuestionar y encontrar respuestas con respecto a un caso o fenómeno particular (IMMERGUT, 2006).

La primera sección del artículo analiza el origen organizativo y funcional de las instituciones policiales en la Nueva República. Para ello, se recurren a fuentes documentales de la época de la Asamblea Nacional Constituyente para mapear cómo las fuerzas de seguridad se posicionaron ante posibles cambios que se asomaban en la política del país. A partir de la tal configuración legal e institucional, la segunda sección analiza la militarización de la policía militar en la contención del crimen. La tercera sección analiza el legalismo de la policía civil, identificando dicho término junto al procesamiento de crímenes junto a jueces y fiscales. La cuarta sección analiza este carácter doble de las instituciones policiales de forma global, planteando consecuencias sociopolíticas que se procesan ante la falta de una visión sistémica y de reformas de las estructuras policiales. Se ha compilado bibliografía especializada en administración pública, ciencia política y trabajos sobre análisis policial, mientras se han utilizado archivos de la Asamblea Constituyente y 
a la legislación en el tema de la seguridad pública. La conclusión señala que la militarización y el legalismo de las fuerzas policiales, estructura organizativa y funcional mantenida desde el comienzo de la última etapa republicana, imprime la lógica general y los límites para tratar el fenómeno de la criminalidad.

\section{LA GESTIÓN POLICIAL EN LA NUEVA REPÚBLICA}

La promulgación de la Constitución en 1988 parecía una "ventana de oportunidad" para discutir nuevos rumbos en la seguridad. No obstante, la nueva Carta alteró de manera tímida las prácticas institucionales y los fundamentos de las instituciones policiales. Tal momento fue especialmente utilizado para reconfigurar el papel de las fuerzas armadas, ya que se buscaba "redefinir las nuevas relaciones civiles-militares para asegurar las futuras instituciones democráticas" (OLIVEIRA, 1987, p.79-93). La seguridad pública fue entendida como "seguridad del orden público", como una tarea a cargo de las policías estatales (Civil y Militar), de la Policía Federal, del Cuerpo de Bomberos, de los Guardias Municipales y de los Agentes Carcelarios (Art.144 CF).

El mantenimiento de una policía de vigilancia y militarizada, resultó de la "inercia" histórica o del interés en preservar dichos órganos como grupos auxiliares del ejército. Considerando la teoría del institucionalismo histórico y path dependence, esa elección re-afirmó una configuración organizativa que difícilmente seria modificada en gobiernos posteriores. Si el combate a la disidencia política no tenía más sentido con el fin de la Guerra Fría, esto tampoco significó que se implementaran cambios sustanciales en el ámbito de la seguridad pública. Esta inercia, que dictó el tono de la redemocratización, se justificaría porque, para las fuerzas del orden, el nuevo contexto estaba repleto de amenazas como la "proliferación de estupefacientes, la crisis de autoridad, la inversión de valores, la facilidad del ciudadano en armarse, las deficiencias del sistema judicial y la violencia urbana"1 (OLIVEIRA, 1987, p.107). Tales amenazas demandaban, por lo tanto, una acción contundente de las fuerzas de seguridad, dejando poco espacio para repensar estructuras organizativas a pesar de los abusos de derechos civiles y políticos cometidos en la dictadura anterior.

Un ejemplo de esa continuidad proviene del análisis de los Diarios de la Asamblea Constituyente (ANC). En la ANC, la comisión responsable por la seguridad pública evitó que se solaparan jurisdicciones de la policía ostensiva/coercitiva y de la policía de investigaciones. Aquí se destacan las enmiendas del diputado Celso Dourado y de Adylson Motta de 1987. La primera intentó remodelar las policías, creando un organismo que concentrara funciones preventivas e investigativas. Sin embargo, este y otros intentos de reforma no prosperaron, pues, como resumido por el constituyente Nelson Jobim:

Es necesario mantener esa tradición brasileña, que ha funcionado en el sentido de establecer la distinción fundamental entre la policía judicial, por un lado, y la policía con función de patrullar, de otro, reservando a las clásicas policías militares la función de la policía ostensiva y a la policía civil la función del escrutinio de la infracción penal, como órgano auxiliar del Poder Judicial. [...] (Diarios de la ANC, p.1904)

Otras enmiendas, como la del diputado Adylson Motta, entretanto, lograron complementar un acuerdo con otros diputados de la época que buscaban una solución que satisficiera a los representantes de las fuerzas de seguridad pública en la ANC.

1 Esta y otras citas están en traducción libre del portugués. 
Si la Policía Civil no pretende ocupar espacios de otros segmentos u organizaciones, tampoco acepta que reduzcan sus prerrogativas, que mutilen sus atribuciones o que otros órganos la tutelen. [...] Se impone así que sea excluida la expresión "preventiva" [sobre una posible inclusión de esta función a la Policía Civil], y esto no es contra la Policía Civil. Los delegados de policía, toda la policía civil está de acuerdo con la supresión, a tal punto que se ha hecho un acuerdo de aprobar este destaque suprimiendo esa expresión para, a continuación, aprobar la enmienda del Constituyente Adylson Motta, que será la próxima enmienda a la siguiente. En esta enmienda, vamos a establecer que la policía civil sea encabezada por Delegados de policía de carrera. Este es el punto neurálgico que importa a la policía civil - la preservación del delegado de policía de carrera en la jefatura de la policía civil, para que no sea la función desvirtuada o la carrera distorsionada o modificada de un gobierno a otro o de acuerdo a las contingencias momentáneas. (Constituyente Gastone Righi, Diarios de la ANC, p.1911)

La actuación de la ANC, en el Capítulo de Seguridad Pública, trabajó con el mecanismo de debate y votación en la Subcomisión de Seguridad, escuchando actores interesados: Asociaciones de la Policía Militar, Clubes de Sargentos y Subtenientes, y la Policía Civil representada por los "delegados" (especie de comisarios jefes) que aseguraron defender los intereses de su corporación. La enmienda Motta fue aprobada con 47 dictámenes favorables, y, según el diputado Bernardo Cabral, esta habría "curado" vicios de la policía civil, impidiendo traer personas ajenas a la función de delegado de policía, "profundo conocedor del derecho y da la investigación", ya que tal cargo había sido desvirtuado por "órdenes superiores de los militares" en los años de la represión. Tal grado de aceptación también se explica por opiniones como las del diputado Luíz Salomão, para quien, por el hecho de definir las directrices de las policías, la enmienda tenía el mérito de

"dar más nitidez y transparencia a las prácticas institucionales" [...] "aislando y creando compartimientos estancos en las funciones de cada corporación responsable de la seguridad pública" (Diarios de la ANC, p.1915).

La Constitución de 1988 reafirmó la misma estructura en la que se erguían las policías, dejando claro que dichas entidades tenían el compromiso de "cuidar" de la seguridad pública, entendida esta como un "derecho y responsabilidad de todos" y ejercida para la "preservación del orden público y de la "incolumidad de las personas y del patrimonio ", según los términos del artículo 144 de la Carta. Sin embargo, en ausencia de una distribución de competencias específicas, la seguridad pública fue entendida como un problema de los estados, ya que las policías militares y civiles permanecieron a cargo de este nivel federativo (RIBEIRO, 2008, p.11). Así, actualmente, la Policía Civil ejerce las funciones de policía judicial y la Policía Militar realiza la función coercitiva y ostensiva (Cap. III, art. 144).

Fenómenos complejos, como la criminalidad y la violencia, dentro del ámbito del federalismo, según Jonathan Rodden (2001), requieren esfuerzos de coordinación, cooperación y negociación para construir alianzas ante los costes políticos de implantación de programas y marcos estratégicos. Pero, en los años 1990, la agenda federal estuvo pautada por programas de transferencia de competencias hacia los estados, y la seguridad pública perdió visibilidad ante las prioridades de la época: reducir la inflación, regular transferencia de recursos, descentralizar políticas públicas e ingresar en la globalización económica de finales del siglo (PALOTTI, 2009). Por ello, en lo que se refiere a la seguridad pública, por regla general, las políticas sirvieron de paliativo a situaciones de emergencia, apareciendo dislocadas de la realidad social o con poca consistencia y articulación con otros sectores administrativos (RIBEIRO, 2008). 
Por vacío político en la esfera federal, apenas en el año 2000 se creó el primer Plan Nacional de Seguridad Pública. No es objetivo repasar ese u otros planes, pero, con base en estudios anteriores (YAURI-MIRANDA, 2013; YAURI-MIRANDA \& VÉLEZ, 2017), se puede afirmar que la mayoría de estos, aunque hayan mejorado el diagnóstico de la realidad social y de los ejes que atraviesan la acción delictiva, aún carecen de esfuerzos interinstitucionales y de interesectorialidad pese a los cortos avances iniciales a nivel local, como en el caso de las policías comunitarias y las Unidades Policiales de Pacificación.

Sea por falta de una acción integral para ejecutar los Planes de Seguridad, sea por límites de coordinación dentro de los Estados y para sistematizar la construcción de datos, el modelo de seguridad pública ha recaído muchas veces en las estados. Estos, a su vez, han depositado su confianza en la expertise de sus fuerzas policiales, las cuales, como mencionado, han sabido defender sus líneas organizativas y funcionales desde la refundación constitucional. Siendo así, a parte del diseño legal en el ámbito de seguridad pública, es esencial explorar el diseño funcional de estos órganos.

\section{UNA MILITARIZACIÓN FUNCIONAL}

Como la policía tiene que enfrentar organizaciones violentas, ilegales y para-estatales (grupos que emulan el monopolio de la violencia del Estado en ciertos territorios), una respuesta de corte bélico podría ser vista como algo natural y deseable por parte de la ciudadanía. Policías como corporaciones militarizadas existen en inúmeros países, incluso en escenarios democráticos y/o pacíficos. No obstante, una particularidad brasileña es que la militarización haya permanecido en una estructura organizacional y funcional estanque (aplicada solamente a organizaciones policiales con funciones exclusivas de prevención y disuasión y cuyo perfil se aplica a todos sus agentes internos), con amplia discrecionalidad interna y bajo control externo. Así, en vez de entenderla como una característica inherentemente negativa, se cuestiona cómo la militarización es aplicada y cómo esta tiene una funcionalidad dentro del sistema de seguridad pública de Brasil. Esta característica es anterior a la Carta de 1988 y se mantuvo como uno de los ejes que sostienen la concepción de la seguridad pública, una práctica enraizada en la idea de que la seguridad se asemeja a "preservar el orden público". Además, la estructura militarizada y estanque para prevenir y disuadir el crimen en las calles, no ha sido acompañada por un eficiente control externo, el cual se reduce al boletín de ocurrencia, momento de encause de la acusación criminal frente a las Policías Civiles, y al trabajo de las oidorías. El control externo sobre las operaciones y el modus operandi de los agentes militarizados ha permanecido en una zona gris y se ejerce de manera discreta y a posteriori, en la mayoría de los estados.

A través de un enfoque de redes, los vínculos formales e informales marcan la asimetría de información, capacidad y poder entre actores políticos (SCHNEIDER, 2005). Por ello, el contacto con altas esferas gubernamentales y extra-gubernamentales, incluso de vertiente criminal, convierte a las Policiales Militares en actores clave. En estos se decantaría una función mediadora que confiere conocimientos y potestades que sirven de correa de transmisión entre esas dos esferas. En esta función, el alto poder de discrecionalidad es identificable y peligroso. De ahí la necesidad de su control externo. No obstante, el control se ha eludido con la excusa de que no hace falta un escrutinio de aquellos que buscan "defender" la sociedad frente al crimen. Mientras tanto, una tenue frontera separa instituciones de contención del crimen de asociaciones o individuos infractores, ya que las prácticas de ambos lados se mimetizan. La "guerra al crimen" y a las drogas ha facilitado instituciones policiales permeadas por métodos violentos e ilegales y que muchas veces permanecen impunes por diversos motivos. Parte de esta impunidad 
tiene que ver incluso con el papel de las fiscalías y de ciertas voces que eximen la violencia de "héroes" uniformados en un frente de batalla².

Por otra parte, en una institución vertical, la convergencia de poder excesivo en la cúpula organizacional, hace que las policías militares se conviertan en brazos políticos y administrativos de la voluntad de los gobiernos estatales. En las últimas décadas, han surgido problemas de formación, de renovación de cuadros en una estructura muy rígida que se especializó en el manejo de armas y en el hecho delictivo. Tales elementos son esenciales pero cubren muy parcialmente una realidad que comporta múltiples ejes que atraviesan las redes criminales (CERQUEIRA, 2007). Esa especialización en la disuasión termina catalizando un uso desproporcionado de la fuerza y la violación de derechos políticos y civiles. Sea por los desvíos de poder al combatir la criminalidad, sea por responder a los dictados y vicisitudes de los gobiernos de los estados (algunos nuevamente sumergidos en una crisis política y fiscal, como en los años 90), todo ello acaba por engendrar un perfil ambiguo frente a valores democráticos. La idea de una sociedad más igualitaria colisiona frontalmente con mecanismos desproporcionados y represivos en una sociedad de desiguales, y la policía "paga ese precio [y esa ambigüedad], pues se presenta manchada. Su semi-legitimidad la transforma en un brazo de acción y en un chivo expiatorio de los conflictos no resueltos satisfactoriamente" (KANT DE LIMA, 2007, p.84). En una explicación de carácter socio-cultural más amplio, Teresa Caldeira (2000) ya manifestaba la existencia de una democracia "disyuntiva". Es decir, una democracia disfuncional presente alrededor del mundo, pero que, en Brasil, se hace notable por el hecho de que, para una expresiva población del país, los derechos civiles están deslegitimados por la criminalidad y por la violencia que se cometen también por instituciones oficiales.

Estos hechos se mantienen, sobre todo, en comunidades segregadas de las metrópolis (UNODC, 2011, 2013; PNUD, 2014). En lugar de prevenir o resolver conflictos, a menudo se ha optado por la supresión violenta de los conflictos y por una gestión de la seguridad que se confunde con una "gestión policial de la criminalidad" de tinte utilitarista, que se materializa en un tacto para contener el crimen en potencial (o en marcha) de infracciones "pequeñas" en un mundo que debería cubrir redes transnacionales de narcotráfico, de corrupción y blanqueo de capitales. En tal centralismo, sin embargo, hay pocos estudios de opinión o de encuestas con las fuerzas de seguridad, especialmente las militares, que permitan inferir una visión interna de las policías ${ }^{3}$. Ante tal limitación cognitiva, prevalece la sensación de que, bajo la óptica de esas corporaciones, la legitimidad y el éxito de sus acciones parecen depender de lo que el Estado y las altas jerarquías policiales desean para la sociedad, y no de lo que la propia policía y sociedad reivindican.

Por lo tanto, las policías militares aparecen como actores centrales pese a sus limitaciones para combatir el crimen. Estas se relacionan con otros puntos de la red influyendo en las prácticas de esa gestión, adoptando una postura defensiva y conservadora con respecto a sus prácticas u operaciones (SOUZA, 2011). En los intentos de estructurar esas instituciones o de reconsiderarlas en una gestión más sistémica, no se puede ignorar la confrontación con elementos organizacionales y funcionales que marcaron estos actores. Los antecedentes, por lo tanto, son importantes, y el "grado de centralización en el mando de estas fuerzas también tiene que ver con las tradiciones establecidas en los orígenes de la policía" (BEATO FILHO, 1999, p.11). En este caso, argumentamos que momentos de refundación del orden y de sus instituciones, como la Constitución de 1988, ofrecieron oportunidades para readaptar este tipo de organizaciones. No obstante, el

2 "PMS, juizes, promotores e nós: o complexo nó da violência policial". El País, 23 de Julio de 2017. Disponible en: https://brasil.elpais.com/ brasil/2017/07/21/politica/1500662148_452392.html, consulta en 25/07/17.

3 Algunos policias adoptan una mentalidad bélica en la que matar significa sobrevivir, sucumben a la presión de sus colegas y matan para mantener su estatus en el escuadrón, otros adoptan una filosofía vigilante tras concluir que el sistema ha fracasado, finalmente, otros creen que los asesinatos traen poder. Véase: Paes de Souza, 2012. 
caso brasileño atesta que la funcionalidad del frente militarizado de las policías ha prevalecido. Las policías continúan siendo un eje de respuesta incremental bélico y un frente inseparable para tratar la criminalidad.

\section{LEGALISMO POLICIAL}

Al mismo tiempo, se ha institucionalizado una práctica de nivel administrativo, pero de esencia jurídica, en la acción de las Policías Civiles y de la Policía Federal. Esa práctica consiste en el "inquérito" policial, fase administrativa donde la acción pre-procesual se convierte en una etapa interna de la policía, en la cual los criterios de la jefatura (de los comisarios o "delegados") orientan el encause de la investigación y sirven para preparar las fuentes que serán utilizadas en la imputación. Aunque estos poderes adicionales y preliminares se encuentren en toda organización policial, la característica brasileña es que estas policías lograron establecer un mecanismo discrecional considerable, pues acaban regulando el ritmo y el tono de la acusación, decidiendo el formato del inquérito y si este será utilizado para activar cualquier sentencia judicial. Como la carrera de esas autoridades en Brasil es una prerrogativa exclusiva de abogados, el inquérito atiende un perfil extremadamente legalista dentro de las comisarias, cuando su función es auxiliar jurídicamente la persecución criminal sin convertirse en un ente judicial a más.

La acusación con respaldo de las fiscalías, casi inexistente en los tiempos del autoritarismo militar, se ha constituido como pieza que gira alrededor de la acción de las propias comisarías. Por ello, tan grave como la militarización excesiva en el cuerpo y formación de las Policías Militares, ha sido el "legalismo" de las Policías Civiles, lo que se traduce en duplicidad de funciones y en lentos procesos jurídicos (BARROSO, 2004). Adicionalmente, la hegemonía de la cultura jurídica en el ámbito policial investigativo ha puesto en ruta de colisión a las autoridades policiales (comisarios) contra los agentes de campo y forenses. Para estos últimos, la exclusividad de comando de un perfil jurídico reduciría la capacidad de respuesta policial, creando una cúpula organizativa ajena a reformas en el ámbito de recursos humanos, de personal y de carreras. Estos conflictos internos serían un caso típico de organizaciones con connotaciones rígidas, como la policía, en la que los rangos superiores tienden a una perspectiva más administrativa de sus corporaciones. "Como tal, ellos [los altos rangos] creen que el organograma refleja la jerarquía y el flujo de comando de la organización." Sin embargo, en el otro extremo, en los rangos inferiores hay "una ocupación altamente discrecional y que para ser ejecutada correctamente requiere un alto grado de autonomía e iniciativa para requerir cambios en la organización", sobre todo ante fenómenos como la criminalidad organizada (ELIZABETH IANNI, apud BEATO FILHO, 1999, p.11).

Por otra parte, para Walter Silva Junior (2009), las diversas modificaciones traídas por la Constitución de 1988 no cambiaron el Código de Procedimiento Penal (CPP) de 1941 de manera sistemática. Si la calidad del CPP no puede medirse únicamente con el número de alteraciones, este ha mantenido durante muchas décadas una relación poco flexible entre jueces y fuerzas policiales, basada incluso en morosas transcripciones de carácter jurídico desde la compilación de pruebas durante la fase del inquérito. En 2008 un conjuntos de leyes ( $N^{\circ} .11 .689,11.690$ y 11.719) modificó los dispositivos del CPP en los siguientes ejes: 1) fortalecimiento del sistema acusatorio, a través del juicio de evidencia; 2 ) mejores garantías para los acusados; 3) celeridad y juicio oral; 4) eficiencia en la búsqueda de asistencia jurídica; 5) revalorización de la figura de la víctima (MENDONÇA, 2008, p.76). Este paquete legislativo tuvo el objetivo de reequilibrar la imparcialidad del juez y reglamentar el procedimiento penal de acuerdo con la no violación de las normas constitucionales en la imputación y asignación penal. Pero, por haber preservado intocada la fase del inquérito policial y su actividad notarial emanada del legalismo policial, la reforma ha engendrado 
un carácter dual al CPP de Brasil, el cual aún se entiende como acusatorio mixto de fuerte tendencia inquisitiva en su praxis. Además, la normativa tampoco ha ayudado a resolver el problema de la duración de los procesos penales, puesto que los puntos de "asfixia" del sistema, aparte de situarse en la fase del inquérito, también se sitúan en la apelación y lentitud hacia instancias superiores, como los Tribunales Superiores de Justicia (FUDOLI, 2008, p.180).

En lo que respecta a la Fiscalía, muchos países han discutido el significado y el alcance de la dirección funcional de la investigación criminal: si a cargo de la policía o de la Fiscalía. En Brasil, pese a que la Constitución Federal mencione a los fiscales (Ministerio Público) como agentes de control externo de la actividad policial, no hay mención específica sobre la forma o la consistencia de este control (art. 129, CF 1988). Es más, en Brasil históricamente la policía ha mantenido mejores relaciones con la justicia que con la Fiscalía (Cnf. Centro de Estudios de la Justicia de las Américas, en: RIEGO Y VARGAS, 2015). La relación entre fiscalías y las policías judiciales ha sido constantemente áspera respecto a la titularidad de la acción penal, sea por conflictos de prerrogativas en esta materia, sea por falta de coordinación e institucionalización de prácticas administrativas. Como resultado, en la Fiscalía Federal se acumularon más de 70\% de los inquéritos en el año 2011. En 2016, en torno a 77\% de los inquéritos recibieron "baixa com diligencia", es decir, fueron devueltos a las policías al menos una vez por improcedencia o para reelaboración ${ }^{4}$. Como reflejo de esa desconexión, menos del $50 \%$ de homicidios fueron clarificados, en cuanto a circunstancias y autores, en la primera quincena del siglo5.

Por lo tanto, la red de gestión de la seguridad brasileña presenta varias fracturas, sea entre los rangos superiores e inferiores en materia de organización policial, sea en el diálogo inter-institucional, como entre estas y las Fiscalías. Incluso el reciente suceso de operaciones anti-corrupción, como la operación Lava Jato, ha dependido en gran medida de contactos personales entre delegados y fiscales en sus primeras fases. Por ello, si la militarización y el legalismo marcaron el perfil de la seguridad y afectan las relaciones con otros actores políticos para procesar la criminalidad, a seguir postulamos algunas consecuencias de esas prácticas para la seguridad pública de una forma global.

\section{CONSECUENCIAS SISTÉMICAS}

La militarización y el legalismo de las policías son condiciones esenciales para entender el perfil de la acción contra el fenómeno del crimen. Dentro de la teoría de los legacy constraints esas condiciones, aunque no sean absolutas, comprueban que la militarización y el legalismo han servido para canalizar estructuras organizativas, relaciones institucionales y hasta prácticas informales de las policías. Por ello, ante las limitaciones de una gestión centrada en las policías como frentes de acción para resolver un fenómeno que escapa tanto a capacidades estatales como al sector de la seguridad, la convivencia en muchos espacios públicos se constituye en desafío a largo plazo. Por tales aspectos, creemos que se consolida una salida "individualista" y otra "conservacionista" en materia de la seguridad pública en tal país.

Una salida "individualista" deriva a partir de la sensación fáctica y subjetiva de inseguridad y miedo que se asocia a ciertos espacios. Ante el desajuste entre la cobertura de la seguridad promovida y la incidencia

4 "Dados do Ministério Público - Um Retrato". 2011; 2016. Disponible en: http://www.cnmp.mp.br/portal/publicacoes/244-relatorios. Consulta en Ene. 2018; Véase: "O Pingue Pongue dos Inquéritos". Michel Misse. Disponible en: <http://www.comunidadesegura.org/pt-br/ MATERIA-o-pingue-pongue-do-inquerito-policial> Dic. 2017.

5 En este índice hay discrepancia entre las unidades federales, pero las cifras raramente superan el 50\% de los casos. En la fecha, se planteó incluso crear un sistema nacional para atenuar este déficit. Véase: "Ministerio de Justiça. Investigação Criminal de Homicidios", Cadernos Temáticos, 2014 
criminal amplificada por discursos alarmistas en la comunicación, se favorecen salidas "individualistas" en una multiplicidad de espacios privados de gestión de la seguridad. Nelson Arteaga Botello (2010) ejemplifica esos espacios como vecindarios, centros comerciales, edificios privados y gubernamentales, parques, distritos de negocios, lugares de trabajo, así como la implementación de políticas de seguridad en zonas consideradas como "peligrosas", regularmente favelas y zonas marginadas, "donde se establecen políticas destinadas a reducir el aparente riesgo de ser víctima de cualquier tipo de delito o crimen" (ARTEAGA BOTELLO, 2010, p.172).

Con ello, ya no se piensa tanto en jurisdicciones estables (a nivel de país, estado o municipio), sino en micro espacios delimitados y fragmentados donde se aplica el orden. Aquí, el componente táctico y estratégico de la militarización son esenciales para acompañar y vigilar el cierre de espacios por parte de algunas franjas de la población preocupadas en defender su estilo de vida frente a la incidencia de la criminalidad. Entre los espacios cerrados y protegidos, se sitúan calles y avenidas que no necesariamente despiertan una sensación de protección. Con ello, la expansión de circuitos de vigilancia y de controles en la circulación de la población, con el fin de encontrar sospechosos o personas ajenas a los espacios protegidos, consolida, en determinadas áreas de Brasil, la idea de evitar que circule el peligro y, entre un espacio y otro, se aísle el miedo (LEEDS, 2017). Se conforman, así, archipiélagos de seguridad, donde cada micro espacio o ámbito social mantiene su propio territorio, su propio objeto de cuidado y de contención de amenazas. La seguridad, como principio de organización de los espacios, establece puentes que comunican cada una de estas "islas de seguridad público/privada" y constituye una lógica de transacción y comunicación entre estas, semejante, pues, a la Ciudad de Muros y a la Ecología del Miedo.

Por otro lado, la salida "conservacionista" deriva de la sensación de que la gestión de la seguridad debe contribuir a mantener las cotas de seguridad conseguidas, de modo a facilitar la contención de riesgos latentes, como la criminalidad organizada. Es decir, en vez de perseguir una expansión de la seguridad, como un bien público hacia el conjunto de la ciudadanía, se desea conservar lo que se tiene, más que buscar una proyección hacia mayores cuotas de bienestar social. Conforme indica Fernando Vallespín en sus estudios sobre la postmodernidad, contrariamente a lo que ha sido la postura convencional del enfoque político clásico de la modernidad, "desde ese conservadurismo del miedo, el futuro se ve más como la sede de nuevos y casi insolubles problemas que como un lugar más emancipado y de mejor convivencia" (VALLESPÍN, 2010, p.41). Y aunque se puedan interpretar y dar distintos enfoques políticos a ese conservadurismo, incluso en Brasil parece que el presente se encuentra condicionado por la ansiedad y la sensación de vulnerabilidad, por lo menos en el tema de la seguridad. Parece que "no hay ambición de futuro", pues "el futuro ha colapsado sobre el presente". Y si existía una visión de la modernidad como el camino hacia la reconciliación del hombre consigo mismo, la "superación de la escasez, el progreso (...), en los momentos actuales el futuro se nos presenta como la sede de todos los males; no es algo que hayamos de construir desde el presente, sino algo frente a lo que hemos de defendernos" (VALLESPíN, 2010, p.41).

La seguridad en Brasil tiene muchas variables y tal complejidad que naturalmente esta materia se constituye como uno de los mayores desafíos de la agenda pública. Ante el fenómeno de la criminalidad, las salidas que postulamos funcionarían como marcos meta-políticos que incluso engloban las prácticas de las policías discutidas en las anteriores secciones. Ante estas salidas, las medidas estatales en esta materia se presentan como resignatarias y vinculan su performance más al desempeño de tareas de contención y de exclusión de sujetos infractores que a los beneficios sociales y a la articulación con otras políticas y actores. Tales medidas acentúan la dependencia en modelos y en una trayectoria heredada desde los tiempos de la Constituyente. Un modelo donde las policías profundizan su línea incremental 
de contención de amenazas y dejan de lado una línea multidimensional de cara a la complejidad del fenómeno de la criminalidad, renunciando, así, a una búsqueda de mayores niveles sistémicos de provisión de seguridad hacia la ciudadanía.

\section{CONCLUSIÓN}

Este estudio ha comprobado que, en los orígenes de la última etapa republicana, hubo una defensa por parte de las policías para mantener una doble caracterización del cuadro organizativo y funcional ante el crimen. Esta inercia funcional ha sido directamente responsable por permitir acciones reactivas y estanque ante el crimen, marcando tanto el perfil de los actores como las propias políticas en este tema. Por un lado, esta inercia ha permitido canalizar el uso de la fuerza en una cadena de acciones belicistas, materias que los estados federados han aplicado en distintos grados, pero con tintes de desproporcionalidad y falta de control externo. Por otro lado, tal cuadro y legado histórico ha permitido una discrecionalidad acentuada del inquérito para dictar el tono y el ritmo del procesamiento penal ante la justicia. Aunque estos aspectos hoy se presenten como naturalizados, hay que recordar que estos fueron defendidos en la última Constitución a finales del siglo pasado. Desde entonces, la relación de las policías con otros actores de la gestión de la seguridad ha sido marcada por conflictos internos o externos y por la falta de coordinación y flexibilidad administrativa, aunque no únicamente por cuestiones vinculadas al tratamiento de delitos.

La especialización en tareas militarizadas y de perfil legalista también han sido responsables, en cierta medida, por una desarticulación que compromete el tratamiento de la criminalidad. Se han formado desniveles de actuación de las policías militares, entendidas como frentes de guerra ante el crimen, que dependen de su capacidad táctica/operativa y de las vicisitudes estatales. Al mismo tiempo, se han formado fracturas en las policías con función de soporte judicial, entre rangos y la cúpula de estas organizaciones, así como en el resto de la cadena de procedimiento penal, incluso en delitos de gravedad. Por fin, la tendencia inquisitiva del sistema contribuye, por ejemplo, a ignorar la cuestión carcelaria como "vertedero" del "otro", del excedente humano, tema esencial que merece atención en futuros estudios.

Ante un panorama de crimen y violencia, postulamos que se acentúa la tendencia hacia salidas individualistas y conservacionistas en el tratamiento de la criminalidad. Por ello, la gestión de la seguridad, de modo a provisionar más protección al conjunto de la colectividad o promover mayor ciudadanía, aún se traduce en un discurso democrático distante y de práctica volátil. Todo esto pasados 30 años del sueño constitucional, el cual necesita renacer continuamente pese a la violencia criminal y a muchas reacciones igualmente invirtuosas del poder público.

La seguridad pública en Brasil presentó y presenta innumerables variables, lo que la constituye como uno de los mayores desafíos de la agenda pública. De eso se extrae que, el modelo bifronte de la acción policial, en cierto modo, dificulta desplegar nuevas herramientas ante la realidad multidimensional del crimen. Considerando la vida de millones de personas, es difícil establecer hasta qué punto se produjo el anhelo histórico de separación entre el simple orden público, heredera de la dictadura, y la seguridad hacia las personas. Finalmente, aunque las últimas décadas asistieron a un aumento de la capacidad de diagnosticar y promover acciones por parte del poder público, al mismo tiempo, también se verificó la capacidad del poder de la acción criminal y de la violencia, remitiendo al mito de Sísifo como paradigma en el tratamiento de este fenómeno. Ciertamente se ha producido un esfuerzo incesante y útil ante el crimen, pero este se ha mostrado insuficiente y continuamente fatídico. 


\section{REFERENCIAS}

ARTEAGA BOTELLO, N. "Consolidación de los archipiélagos de seguridad en América Latina". Espiral, Estudios sobre Estado y Sociedad, V. 17, n. 49, 2010, pp. 163-195.

BARROSO, L., "Investigação pelo Ministério Público. Argumentos contrários e a favor: A síntese possível e necessária". Parecer. Revista Brasileira de Direito Público. v. 7, n.7, 2004, pp. 213-227.

BEATO FILHO, C. "Políticas Públicas de Segurança e a Questão Policial: Eficiência, equidade e accountability". In: M. A. Melo (Org.), Reforma do Estado e Mudança Institucional no Brasil. Recife, Fundação Joaquim Nabuco e Editora Massangano, 1999.

BRASIL, Câmara Federal de Deputados. Diário da Assembleia Nacional Constiuinte. Anais e Ata de Comissões 1987/1988. Disponible en <http:/www2.camara.leg.br/atividade-legislativa/legislacao/Constituicoes_ Brasileiras/constituicao-cidada/publicacoes/anais-da-assembleia-nacional-constituinte> consulta en May. 2017.

. Constituição da República Federativa do Brasil de 1988. Disponible en <http://www.planalto.gov.br/ccivil_03/ constituicao/constituicao.htm> consulta en May. 2017.

CALDEIRA, T. Cidade de Muros: Crime, Segregação e Cidadania em São Paulo. São Paulo, Ed. 34, Edusp, 2000.

CERQUEIRA, E. \& CARVALHO, J. L. “O jogo dos sete mitos e a miséria da segurança pública no Brasil”. In: M. V. Gonçalves da Cruz; E. Cerqueira (Org.), Homicídios no Brasil. Rio de Janeiro, Editora FGV, 2007.

COLLIER, R. B. \& COLLIER, D. Shaping the political arena. Notre Dame: University of Notre Dame Press, 2002.

DAMMERT, L. "Dilemas da Reforma Policial na América Latina”. In: H. CARUSO; J. MUNIZ; A. C. C. BLANCO (org.), Polícia, estado e Sociedade: Práticas e Saberes Latino-americanos. Rio de Janeiro, Publit Soluções Editoriais, 2007.

DAVID, P. A. "Path dependence: a foundational concept for historical social science". Cliometrica, nro. 1, vol 2, 2007, pp. 91-114. Disponible en: https://doi.org/10.1007/s11698-006-0005 (acceso 11/03/2018)

FUDOLI, R. de A. "Lei N. 11.69/08: Reforma no Tratamento das Provas Processuais Penais". In: Reforma processual penal. São Paulo, Imprensa Oficial, 2008.

IMMERGUT, E. M. "Historical institutionalism in political science and the problem of change". In: Understanding Change, 237-259. London: Palgrave Macmillan UK, 2006. Disponible en: https://doi. org/10.1057/9780230524644_17 (acceso 05/03/2018)

KANT DE LIMA, R. "Direitos Civis, Estado de Direito e cultura policial a formação policial em questão". Revista Preleção, v. 1, 2007, pp. 67-87.

LAGOS, M. \& DAMMERT, L. La Seguridad Ciudadana: El problema principal de América Latina. Lima, Latinobarómetro, 2012.

LEEDS, E. "Rio de Janeiro". In: K. KOONINGS; D. KRUIJT (Org.), Fractured cities: Social exclusion, urban violence \& contested spaces in Latin America. New York, Zed Books, 2017, pp. 23-35.

MENDONÇA, A. B. de. "Os Elementos Produzidos Durante o Inquérito e as Provas Antecipadas, Cautelares e Irrepetíveis, segundo a Reforma do CPP". In: Reforma processual penal. São Paulo, Imprensa Oficial, 2008.

MISSE, M. "Reflexões sobre a Investigação Brasileira através do Inquérito Policial". In: Cadernos Temáticos da

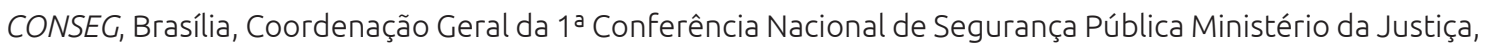
Ano I, ก. 06, 2009. 
OLIVEIRA, J. A. Constituinte e segurança pública. Brasília, Informe do Legislativo, 1987. Disponible en <http:// www2.senado.leg.br/bdsf/bitstream/handle/id/181756/000431257.pdf?sequence=3> (acceso 05/09/2017).

PAES DE SOUZA, A. A educação em direitos humanos na Polícia Militar. Dissertação Mestrado em Direito, USP, mimeo, 2012.

PALOTTI, P. “Descentralização de políticas sociais no federalismo brasileiro: revisitando problemas de coordenação e autonomia". Revista do CAAP, v. 16, 2009, pp. 1-14.

PIERSON, P. \& SKOCPOL, T. "Historical institutionalism in contemporary political science". Political science: The state of the discipline. n. 3, 2002, pp. 693-721.

PNUD, Programa de las Naciones Unidas para el Desarrollo. "Informe Regional sobre Desarrollo Humano". Seguridad Ciudadana con rostro humano: Diagnóstico y Propuestas para América Latina, 2014. Disponible en: http:// www.undp.org/content/dam/rblac/img/IDH/IDHAL\%20Informe\%20completo.pdf, (acceso 11/12/2016).

RIBEIRO, E. "Políticas de Seguridad Pública y Prevención: El Caso Brasileño". In: H. Fruhling (org.), Sistemas de Seguridad Pública en América Latina: Casos Comparados, Santiago de Chile, Centro de Estudios en Seguridad Ciudadana. Boletín N. 7, 2008.

RIEGO, C. y VARGAS, J. E. "Reformas procesales penales en América Latina: Resultados del Proyecto de seguimiento", Santiago de Chile, Centro de Estudios de Justicia de las Américas - CEJA, 2015.

RODDEN, J. "Federalismo e descentralização em perspectiva comparada: sobre significados e medidas". Revista de Sociologia e Política, n. 24, 2005, pp. 36-53.

SCHNEIDER, V. "Redes de políticas públicas e a condução de sociedades complexas". Civitas, Revista de Ciências Sociais, v. 5, n. 1, 2005, pp. 29-58.

SILVA JUNIOR, W. N. da. "Reforma do Código de Processo Penal: Leis N. 11689, N.11.690 E N. 11.719, de 2008". Revista CEJ (Brasília), v. 1, 2010, pp. 20-24.

SOUZA, L. "Políticas Públicas e a área da segurança no Brasil. Debate em torno de um novo paradigma". Caxambu, 35. Encontro Nacional da Anpocs, 2011.

STEINMO, S. "Historical institutionalism". Approaches and methodologies in the social sciences: A pluralist perspective, 2008, pp. 118-138. Disponible en: https://doi.org/10.1017/CBO9780511801938.008 (acceso 13/04/2018).

UNODC. United Nations Office on Drugs and Crime. World Report on Homicides, 2011. Disponible en <http:// www.unodc.org/documents/data-and-analysis/statistics/Homicide/Globa_study_on_homicide_2011_web. pdf> (acceso 26/11/2017).

— . United Nations Office on Drugs and Crime. World Report on Homicides. 2013. Disponible en <http://www. unodc.org/documents/gsh/pdfs/2014_GLOBAL_HOMICIDE_BOOK_web.pdf > (acceso 26/11/2016).

VALLESPÍN, F. "La transformación del Estado como consecuencia de los impactos de la crisis económica". Revista del CLAD Reforma y Democracia, n. 48, 2010, pp. 31-50.

YAURI-MIRANDA, J. R., Criminalidade na América Latina: Políticas de Segurança Pública no Chile e Brasil, da Transição à Democracia. Monografía para Bacharelado em Historia, Faculdade de Filosofía y Ciências Humanas, UFMG, mimeo, 2013.

YAURI-MIRANDA, J. R. \& VÉLEZ, V. A. "Overcoming democratic setbacks with public policies: strategies for anticorruption in Mexico and public security in Brazil." De Política, Revista de la Asociación Mexicana de Ciencias Políticas (Amecip), v.5 ก. 9, 2017, pp. 83-100. 